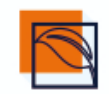 \\ ESTA JOURNAL

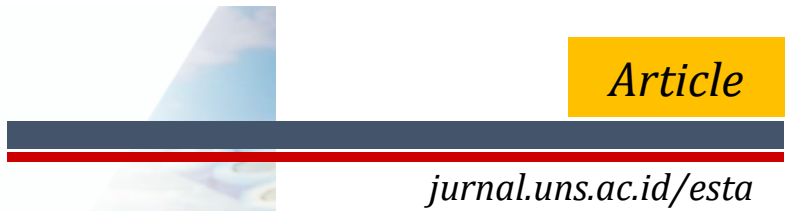 \\ Energy Storage Technology and Applications
}

\section{Zinc Oxalate as a Green Anode Material for Commercial Li-Ion Batteries: a Preliminary Study}

Meidiana Arinawati1,2, Anjas Prasetya Hutama1,2, Enni Apriliyani' ${ }^{1}$, Muhammad Nur

Ikhsanudin ${ }^{1,2}$ and Cornelius Satria Yudha ${ }^{1,2^{*}}$

${ }^{1}$ Chemical Engineering Department, Vocational School, Universitas Sebelas Maret, Jl. Kol. Sutarto 150K

Jebres, Surakarta 57126, Indonesia

${ }^{2}$ Centre of Excellence for Electrical Energy Storage Technology, Universitas Sebelas Maret, Jl. Slamet

Riyadi, 435, Surakarta

*corresponding author : corneliussyudha@staff.uns.ac.id

Received : 09-08-2021; Revised : 11-10-2021; Accepted : 01-11-2021; Published : 01-12-2021

ABSTRACT: Li ion batteries is a crucial energy storage for new and renewable energy (NRE)-based power plant due to its high energy density. However, the anode materials of commercial Li-ion batteries such as graphite and $\mathrm{Li}_{4} \mathrm{Ti}_{5} \mathrm{O}_{12}$ are considered less eco-friendly due to it requirement of high temperature processing which is also uneconomical. In this research, for the first time ever, zinc oxalate was prepared via mild temperature precipitation process and applied as anode material in commercial Li-ion batteries. XRD, FTIR and SEM analysis were conducted to examine the physical and chemical properties of the as obtained zinc oxalate. The effect of precursor concentration was investigated. Chargedischarge analysis shows that zinc oxalate dihydrate as anode material delivered a discharge capacity of $25 \mathrm{mAh} / \mathrm{g}$.

Keyword: Anode, Zinc, Zinc oxalate, precipitation, batteries, Li-ion batteries

\section{Introduction}

A sustainable energy storage technology has become the dream technology of the current era. It is a crucial aspect in clean energy development that involve new and renewable energy (NRE). NREs are highly abundant but sometime produce intermittent energy, such as: solar energy and wind energy. These energy sources have an enormous prospect to be harvested but their dependability is limited by the presence of energy storage. Li-ion batteries (LIBs) are considered as reliable energy storage due to their features such as long shelf life and high energy storage capability. Inside an LIB, there are four main parts namely cathode, anode, separator and electrolyte. The commercial cathode materials in the market are LiFePO4, LiNixMnyCozO2, and LiCoO2. Commercial separator used in LIBs is celgard while commercial anode material is artificial graphite [1]

Graphite can be used as anode material due to its ability to store Li-ion during the charging process. Since it contains carbon, it is considered highly abundant and reliable for LIBs 
commercialization. Carbon based anode is also consistently developed due to its economic benefit [2][3] However, to obtain carbon-based anode, it requires efforts such as high energy consumption and potential organic waste management as a result of carbonization process. A graphitic anode material requires ultra-high temperature process which makes the overall production of graphite less eco-friendly and less economical. Metal oxides have been developed as the next generation of anode materials. Lithiated metal oxides such as $\mathrm{Li}_{4} \mathrm{Ti}_{5} \mathrm{O}_{12}$ (LTO) and $\mathrm{Li}_{2} \mathrm{ZrO}_{3}$ (LZO) have been successfully adapted for commercial LIBs, however the presence of $\mathrm{Li}$, and not to mention the synthesis process are both considered uneconomical [4][5]. Therefore, an anode material synthesized at mild temperature for commercial LIBs application development is highly necessary to obtain a cheap and more sustainable energy storage.

Recently hydroxide of $\mathrm{Ni}$ and Co have been employed as an active material in lithium metal batteries [6][7]. However, $\mathrm{Ni}$ and Co also considered expensive and not eco-friendly. Zinc-based anode material is promising to be applied as anode material [8][9]. It is eco-friendly, cheap and highly abundant. Herein, for the first time ever, we propose a preliminary study of zinc oxalate utilization in commercial Li-ion batteries. Zinc-oxalate or $\mathrm{ZnC}_{2} \mathrm{O}_{4}$ is obtained via aqueous precipitation at various concentration with no further high temperature processing.

\section{Experimental Method}

$\mathrm{ZnSO}_{4} \cdot 7 \mathrm{H}_{2} \mathrm{O}$ obtained from Xiangtan New Sunshine, China was used as the precursor. Oxalic acid dihydrate $\left(\mathrm{H}_{2} \mathrm{C}_{2} \mathrm{O}_{4} \cdot 2 \mathrm{H}_{2} \mathrm{O}\right)$ obtained from Yuanping, China was used as an oxalate source. Both materials were used directly without any purification step.
In equimolar composition, $\mathrm{ZnSO}_{4}$ and oxalic acid were dissolved in separate beakers at various concentration of $0.5 \mathrm{M}$, $1 \mathrm{M}$ and $2 \mathrm{M}$. After the material thoroughly dissolved, the oxalic acid was transferred to a beaker containing $\mathrm{ZnSO} 4$ solution with same concentration. Precipitation reaction occurred and the beaker was continuously stirred for 1 hour at $50{ }^{\circ} \mathrm{C}$ The precipitate was allowed to settle and separated from the liquor using filter paper. The precipitate was washed for three times and dried in an oven. The $\mathrm{ZnC}_{2} \mathrm{O}_{4}$ samples prepared at concentration of $0.5 \mathrm{M}, 1 \mathrm{M}$ and $2 \mathrm{M}$ were labelled as $\mathrm{ZnOx}-\mathrm{A}, \mathrm{ZnOx}-\mathrm{B}$, and $\mathrm{ZnOx}-\mathrm{C}$, respectively.

The as prepared samples were characterized using XRD (MD-10 diffractometer, MTI), FTIR (IR-Spirit, Shimadzu), and SEM (Jeol, Japan). The electrochemical performance test was employed by assembling $\mathrm{ZnOx}$ samples electrode sheet prepared via doctor blade method, separator, and LiNi0.8Mn0.1Co0.102 cathode material into a cell with LiPF6 carbonic solution. The overall process is described elsewhere. The cell was charged and discharged using Neware battery testing system (Neware, China) at working voltage of $2.2-4.3 \mathrm{~V}$ and current density of $20 \mathrm{~mA} / \mathrm{g}$.

\section{Result and Discussion}

Figure 1 displays the FTIR spectra of $\mathrm{ZnC}_{2} \mathrm{O}_{4}$ samples obtained at various concentration. Absorbance peaks observed at wavenumber 400-1600 shows a typical metal oxalate compound while absorbance peak detected at $3400-3300 / \mathrm{cm}$ can be attributed to $\mathrm{H}_{2} \mathrm{O}$ molecule; thus, it can be concluded that hydrate crystal is presence in the sample[9], [10] 


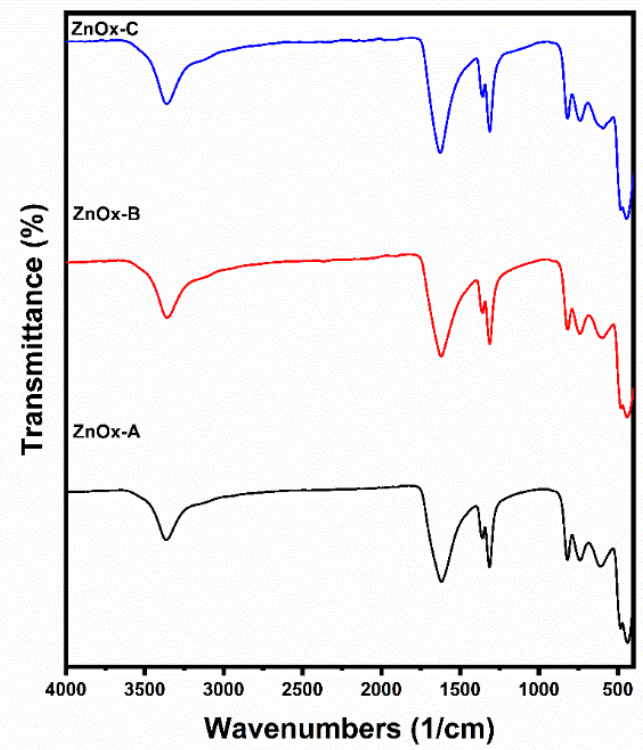

Figure 1. Fourier-transformed infra-red spectra of $\mathrm{ZnC}_{2} \mathrm{O}_{4}(\mathrm{ZnOx})$ powder

Based on previous researches, hydrated crystal often found in the oxalate precipitation. The total amount of hydrate crystal can be estimated by thermal gravimetric analysis[11]. However, it is not conducted in this research. The total hydrate crystal of each sample is x-ray diffraction characterization. It can be assumed that the $\mathrm{ZnC}_{2} \mathrm{O}_{4} \cdot \mathrm{xH}_{2} \mathrm{O}$ samples are obtained with precursor concentration of $0.5 \mathrm{M}, 1.0 \mathrm{M}$, and $2.0 \mathrm{M}$. The effect of concentration is insignificant since the peak intensity are similar between each sample.

Figure 2 presents the $x$-ray diffraction pattern of zinc oxalate ( $\mathrm{ZnOx}$ ) obtained from precipitation process of $\mathrm{ZnSO}_{4}$ solution with oxalic acid solution at equimolar proportion. All of the peaks are similar one to another and can be indexed to JCPDS card no.25-1029. Based on this finding, all of the sample is categorized to a monoclinic structure of $\alpha-\mathrm{ZnC}_{2} \mathrm{O}_{4} \cdot 2 \mathrm{H}_{2} \mathrm{O}$ with space group $\mathrm{C} 2 / \mathrm{c}$ no. $15 \mathrm{~A}$. The solution route of $\mathrm{ZnOx}$ precipitation is proved to be an effective method to produce such product. In the XRD pattern, there are no impurities phase can be observed, hence a pure $\mathrm{ZnC}_{2} \mathrm{O}_{4} \cdot 2 \mathrm{H}_{2} \mathrm{O}$ samples are successfully synthesized[12], [13].

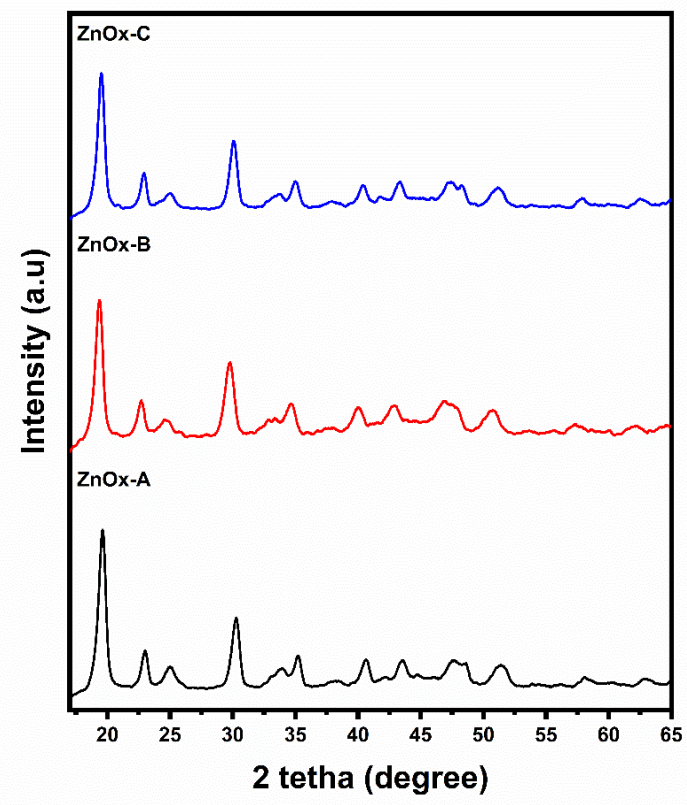

Figure 2. X-ray diffraction of zinc oxalate obtained at various precipitation concentration of (a) $0.5 \mathrm{M}$, (b) $1.0 \mathrm{M}$, and (c) $2 . \mathrm{M}$

SEM image of as obtained zinc oxalate samples is depicted in figure 3. Triangular shaped particle with clear crystal facet can be seen in figure $3 a$. Agglomerated secondary particle consist of sheets-like primary particle can be seen in figure $3 \mathrm{~b}$. Meanwhile, in figure 3c, a denser particle with similar morphology to figure $3 \mathrm{~b}$ can be observed. Based on the figures, it can be concluded that while the concentration difference of the precursors is not significantly affecting the structural and surface chemistry properties of the sample, it is significantly affecting the morphology of the particle. At lower concentration, the particle has a clear facet crystal while in the higher concentration, the particle has sheetlike particle with increase in density. 


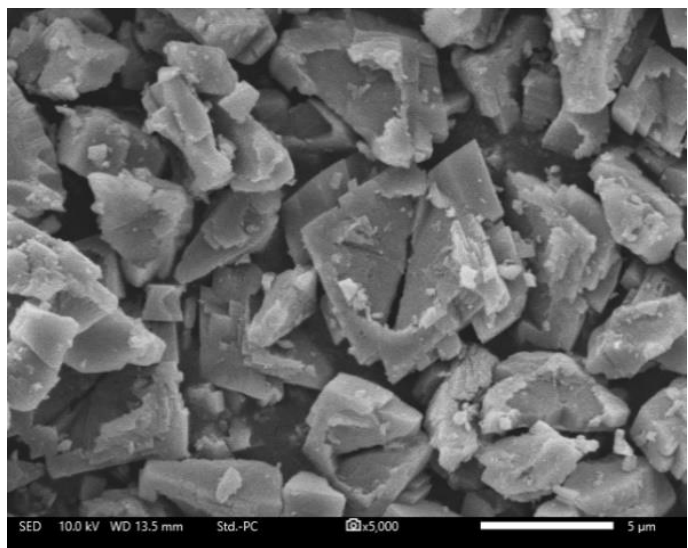

(a)

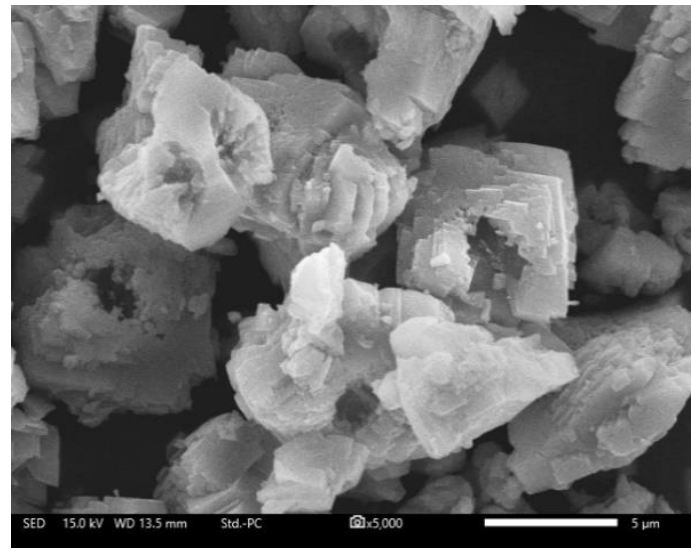

(b)

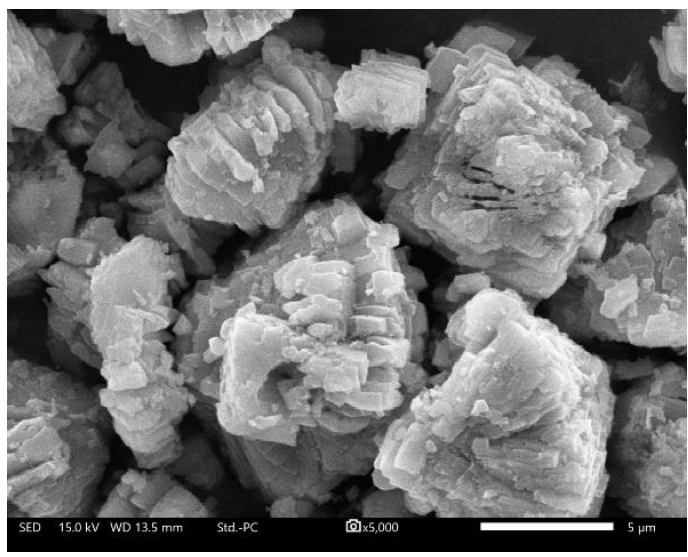

(c)

Figure 3. SEM Image of $\mathrm{ZnC}_{2} \mathrm{O}_{4}$ powder at various precursor concentration of (a) $0.5 \mathrm{M}$, (b) $1.0 \mathrm{M}$, and (c) $2.0 \mathrm{M}$

It can be predicted that during the precipitation, higher concentration results in increase of reaction and crystal nuclei growth. Based on Ostwald ripening mechanism, rapid crystal growth may reach a better distribution of particle sizes and formation of pseudo-spherical morphology. Particle with rough surface and sheet-like particle has higher surface area which affect the Li storage capability. Considerably, $\mathrm{ZnOx}-\mathrm{B}$ and $\mathrm{ZnOx}-\mathrm{C}$ were selected to be tested in the electrochemical performance test[14]-[16].

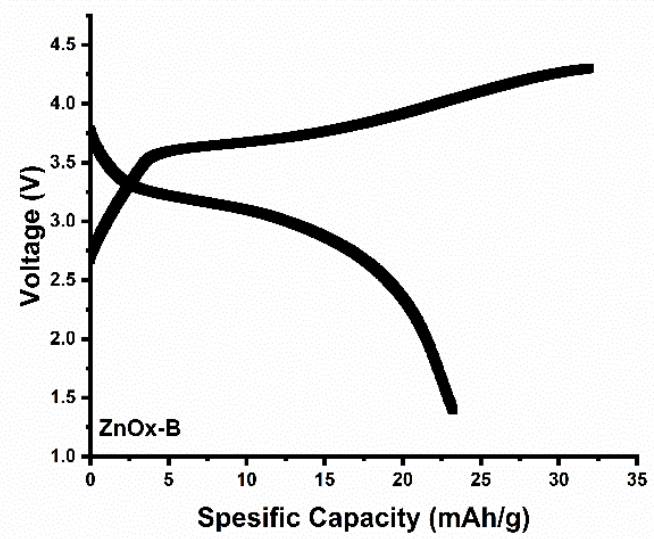

(a)

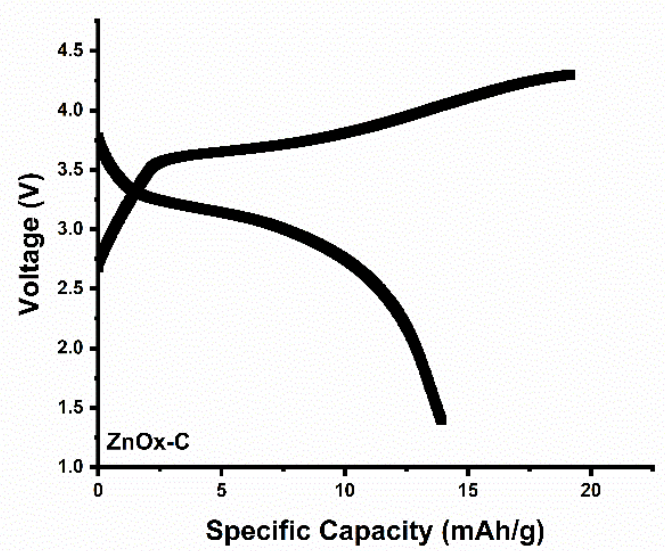

(b)

Figure 4. Charge-discharge analysis of (a) $\mathrm{ZnOx}-\mathrm{B}$ and (b) $\mathrm{ZnOx}-\mathrm{C}$ as anode material in Li-ion batteries

Electrochemical performance testing was performed in a cylindrical battery cell by using the NMC811 $\left(\mathrm{LiNi}_{0.8} \mathrm{Mn}_{0.1} \mathrm{Co}_{0.1} \mathrm{O}_{2}\right)$ as the counter cathode and $\mathrm{ZnOx}$ as an anode and weight basis. The specific capacity of the $\mathrm{ZnOx}$ sample in the cylindrical battery can be seen in Figure 4 . Based on the figure, the specific capacity of $\mathrm{ZnOx}-\mathrm{B}$ is $24 \mathrm{mAh} / \mathrm{g}$ and the specific 
capacity of $\mathrm{ZnOx}-\mathrm{C}$ is $14 \mathrm{mAh} / \mathrm{g}$. The initial charging capacity is near $200 \mathrm{mAh} / \mathrm{g}_{\text {cathode }}$ (figure is not shown), however the discharge capacity is only $10 \% .90 \%$ of irreversible Li storage is occurred due to the conversion of active $\mathrm{Li}$ to inactive $\mathrm{Li}$ through chemical reaction of $\mathrm{Li}$ ion with $\mathrm{Zn}$-oxalate to $\mathrm{LiC}_{2} \mathrm{O}_{4}$. However, the $\mathrm{ZnOx}$ sample is considered functional since it can deliver discharge capacity of $24 \mathrm{mAh} / \mathrm{g}_{\text {anode }}$ and can be improved by tuning the size and morphology of the particle. This opens for possible future projects on developing green anode material for Li-ion batteries.

\section{Conclusions}

A pure zinc oxalate dihydrate powder with good structural characteristic is successfully synthesized. The effect of precursor concentration does not significantly alter the structural characteristic of the products, but highly affected the morphology features. Based on charge-discharge analysis, the as obtained zinc oxalate dihydrate as an anode material can deliver a discharge capacity of 24 $\mathrm{mAh} / \mathrm{g}$ of anode in commercial batteries using NMC811 as the cathode material.

\section{Acknowledgment:}

The authors are grateful for the support of Centre of Excellence for Electrical Energy Storage Technology during the research and the making of manuscript.

\section{Reference}

[1] B. Dunn, H. Kamath, and J. M. Tarascon, "Electrical energy storage for the grid: A battery of choices," Science (80-. )., vol. 334 , no. 6058, pp. 928-935, 2011, doi: 10.1126/science.1212741.

[2] Z. Jian, W. Luo, and X. Ji, "Carbon Electrodes for K-Ion Batteries," J. Am. Chem. Soc., vol. 137, no. 36, pp. 1156611569, 2015, doi: 10.1021/jacs.5b06809.

[3] C. S. Yudha et al., "Fast production of high performance LiNi0.815Co0.15Al0.03502 cathode material via urea-assisted flame spray pyrolysis," Energies, vol. 13, no. 11, 2020, doi: $10.3390 /$ en 13112757.

[4] S. Ito et al., "A rocking chair type allsolid-state lithium ion battery adopting Li 20-ZrO2 coated LiNi0.8Co0.15Al 0.0502 and a sulfide based electrolyte," J. Power Sources, vol. 248, pp. 943-950, 2014, doi: 10.1016/j.jpowsour.2013.10.005.

[5] A. Purwanto et al., "High Performance of Salt - Modified - LTO Anode in LiFePO 4 Battery," Appl. Sci., vol. 10, no. 7135, pp. 1-14, 2020, doi: 10.3390/app10207135.

[6] X. Zhu, Y. Zhong, H. Zhai, Z. Yan, and D. Li, "Nanoflake nickel hydroxide and reduced graphene oxide composite as anode materials for high capacity lithium ion batteries," Electrochim. Acta, vol. 132, pp. 364-369, 2014, doi: 10.1016/j.electacta.2014.03.132.

[7] L. Wang, G. Zhang, Q. Liu, and H. Duan, "Recent progress in Zn-based anodes for advanced lithium ion batteries," Mater. Chem. Front., vol. 2, no. 8, pp. 1414-1435, 2018, doi: 10.1039/c8qm00125a.

[8] Y. Wang, X. Zheng, Q. Qu, G. Liu, V. S. Battglia, and H. Zheng, "A novel maleic acid/graphite composite anode for lithium ion batteries with high energy and power density," Carbon N. Y., vol. 132, pp. 420-429, 2018, doi: 10.1016/j.carbon.2018.02.043.

[9] C. S. Yudha, M. Rahmawati, A. Jumari, A. P. Hutama, and A. Purwanto, "Synthesis of Zinc Oxide ( $\mathrm{ZnO}$ ) from Zinc BasedFertilizer as Potential and Low-Cost Anode Material for Lithium Ion Batteries," in ACM International Conference Proceeding Series, 2020, pp. 1-6, doi: 10.1145/3429789.3429860.

[10] H. J. Oh et al., "Nickel oxalate dihydrate nanorods attached to reduced graphene oxide sheets as a high-capacity anode for rechargeable lithium batteries," NPG Asia Mater., vol. 8, no. 5, pp. e270-8, 2016, doi: 10.1038/am.2016.59.

[11] C. Ya-Li, L. Liu, J. Dian Zeng, and X.-Q. Xin, "One-step Solid-state Synthesis and Characterization of Two Kinds of ZnC 20 4 - 2H 2 O Hollow Nanostructures," Chinese J. Chem., no. 23, pp. 539-542, 
Arinawati, et. al., 2021, Zinc Oxalate as a Green Anode Material for Commercial Li-Ion Batteries: a Preliminary Study

2010.

[12] L. Guo, Y. Ji, H. Xu, Z. Wu, and P. Simon, "Synthesis and evolution of rod-like nano-scaled $\mathrm{ZnC} 2 \mathrm{O} 4 \cdot 2 \mathrm{H} 2 \mathrm{O}$ whiskers to ZnO nanoparticles," J. Mater. Chem., vol. 13, no. 4, pp. 754-757, 2003, doi: $10.1039 / \mathrm{b} 210472 \mathrm{e}$.

[13] N. D. Cooper, "Complete Kinetic and Mechanistic Decomposition of Zinc Oxalate with Characterization of Intermediates and Final Oxide," 2015.

[14] S. Muljani, H. Setyawan, G. Wibawa, and A. Altway, "A facile method for the production of high-surface-area mesoporous silica gels from geothermal sludge," Adv. Powder Technol., vol. 25, no. 5, pp. 1593-1599, 2014, doi: 10.1016/j.apt.2014.05.012.

[15] Y. Li, X. Li, Z. Wang, H. Guo, and J. Wang, "An Ostwald ripening route towards $\mathrm{Ni}$ rich layered cathode material with cobalt-rich surface for lithium ion battery," Sci. China Mater., vol. 61, no. 5, pp. 719-727, 2018, doi: 10.1007/s40843-017-9162-3.

[16] Q. Zhu, H. Xiao, R. Zhang, S. Geng, and Q. Huang, "Effect of impeller type on preparing spherical and dense Ni1-x-yCoxMny(OH)2 precursor via continuous co-precipitation in pilot scale: A case of $\mathrm{Ni0} \cdot 6 \mathrm{Co} 0 \cdot 2 \mathrm{Mn} 0 \cdot 2(\mathrm{OH}) 2, "$ Electrochim. Acta, vol. 318, pp. 1-13, 2019, doi: 10.1016/j.electacta.2019.06.008. 